\title{
Waterjet submucosal dissection of porcine esophagus with the HybridKnife and ERBEJET 2 system: a pilot study $\square$
}

\section{(ㅇ) $\circledast \Theta$}

\author{
Authors \\ Daisuke Akutsu' ${ }^{1}$, Hideo Suzuki², Toshiaki Narasaka' ${ }^{1}$, Masahiko \\ Terasaki', Tsuyoshi Kaneko' ${ }^{1}$, Hirofumi Matsui ${ }^{1}$, Yuji Mizokami², \\ Ichinosuke Hyodo \\ Institutions \\ 1 Department of Gastroenterology, University of Tsukuba, \\ 1-1-1, Tennodai, Tsukuba, Ibaraki, Japan \\ 2 Division of Endoscopy, University of Tsukuba Hospital, \\ 2-1-1, Amakubo, Tsukuba, Ibaraki, Japan
}

submitted 28.6.2016

accepted after revision $\quad 24.10 .2016$

\begin{abstract}
Bibliography
DOI http://dx.doi.org/10.1055/s-0042-122335 |

Endoscopy International Open 2017; 05: E30-E34

(c) Georg Thieme Verlag KG Stuttgart · New York

ISSN 2364-3722
\end{abstract}

Corresponding author

Daisuke Akutsu, MD, Department of Gastroenterology, University of

Tsukuba, 1-1-1, Tennodai, Tsukuba, Ibaraki 305-8575, Japan

Fax: +81-29-8533218

dakutsu11@yahoo.co.jp

\begin{abstract}
Background and study aims Esophageal endoscopic submucosal dissection (ESD) is technically difficult because of narrow working spaces and ease of perforation due to the lack of serosa. HybridKnife is a recently developed ESD device that is combined with the high pressure waterjet ERBEJET 2 system to lift mucosa. We hypothesized that this waterjet could make submucosal dissection safer and studied this in porcine esophagus.

Materials and methods Water pressures of 30-70 bar were tested to determine the appropriate pressure for waterjet ESD with HybridKnife (WJ-ESD) in one pig. WJ-ESD safety and completion were compared with those of conventional ESD using DualKnife (C-ESD) as a reference. Each of three virtual esophageal lesions in two pigs were resected alternatively using both methods from the lower to upper esophagus. For WJ-ESD, the submucosa, apart from hard fibrous tissues, was dissected using water pressure alone.

Results Using 50 bar of water pressure resulted in the best balance between proper dissection and view-disturbing water backflow. The dissection speeds for the lower, middle, and upper esophagus were $0.2,0.9$, and $0.2 \mathrm{~cm}^{2} / \mathrm{min}$ in 50 bar WJ-ESD and $1.1,0.5$, and $1.0 \mathrm{~cm}^{2} / \mathrm{min}$ in C-ESD, respectively. Minor bleeding was frequent in WJ-ESD, but was easily stopped by electrocoagulation with the same needle. No perforation was observed in either procedure. Thermal damage to dissected tissues appeared mild, and the extent of muscle injury was lower for WJ-ESD $(4,6$, and $8 \%$ ) compared with C-ESD $(14,16$, and $7 \%)$.

Conclusions WJ-ESD could be completed safely for porcine esophagus with less damage to the muscle layer compared with C-ESD.
\end{abstract}

\section{Introduction}

Endoscopic submucosal dissection (ESD) has become the standard procedure for en bloc resection of gastrointestinal tract tumors [1-7]. ESD requires advanced skills and a long learning curve to achieve consistent and complete procedures $[8,9]$. In addition, ESD has the disadvantage of high complication rates [10]. Specifically, since the esophageal wall is thin and its lumen is narrow, esophageal ESD complications such as perforation and active bleeding can be frequent and difficult to treat $[1,11-15]$.

HybridKnife is a unique ESD device that provides high pressure water flow on the top of the stainless steel tube. It has an outer diameter of $2.1 \mathrm{~mm}$ and a length of $2.2 \mathrm{~m}$. The tip of the stainless steel tube incorporates a microcapillary lumen with a diameter of $150 \mu \mathrm{m}$ [16-20]. When used with the waterjet generator ERBEJET 2 System, HybridKnife enables needleless infusion for submucosal elevation as well as electrical cutting and coagulation of visible vessels without changing devices [21-
24]. The combination of HybridKnife and ERBEJET 2 can attain water pressures of up to 80 bar in the endoscopy field. Recent experimental studies of other prototype waterjet dissectors showed less damage to the gastrointestinal muscular layer [ 9 , $25,26]$. Thus, we hypothesized that the high pressure waterjet generated by HybridKnife and ERBEJET 2 might enable dissection of the submucosal layer with less tissue damage and improve the safety of esophageal ESD. The primary aims are to find the appropriate water pressure for waterjet ESD and to evaluate the safety and feasibility of warterjet dissection using HybridKnife in an anesthetized porcine model.

\section{Materials and methods}

\section{Animals}

Two healthy 3-month-old domestic pigs weighing $50 \mathrm{~kg}$ were used. The pigs were deprived of food, but water consumption was allowed for 24 hours before the procedure. All procedures were performed with the animals placed in the left lateral decubitus position on the operating table under general anesthe- 
sia. The pigs were premedicated with intramuscular ketamine $(10 \mathrm{mg} / \mathrm{kg})$ and xylazine hydrochloride $(2 \mathrm{mg} / \mathrm{kg})$. Isofluorane gas $(1.5 \mathrm{~L} / \mathrm{min})$ was used to maintain anesthesia under mechanical respiratory assistance. Vital signs and physiological parameters were monitored during the procedures. The endoscope was inserted through a flexible sterile overtube (MD48618, Sumitomo Bakelite, Tokyo, Japan). At the end of procedure, the pigs were euthanized, and necropsy was performed immediately. This study was approved by the Institutional Animal Care and Use Committee of the University of Tsukuba.

\section{Endoscope, ESD devices, and other equipment}

A forward-viewing single channel gastrointestinal endoscope (GIF-Q260]; Olympus Medical Systems, Tokyo, Japan) with a conical transparent cap attached to the tip was used for all procedures. We used a HybridKnife T-Type (Erbe Elektromedizin, Tübingen, Germany) for waterjet dissection and DualKnife with a 1.5-mm long needle (KD-650U, Olympus Medical Systems, Tokyo, Japan) for circumferential cutting and conventional dissection. The modular VIO generator (VIO 300D; Erbe Elektromedizin, Tübingen, Germany) was used as the radiofrequency surgical system. The VIO was set to modes ENDO CUT Q 2-3-2 for circumferential cutting and SWIFT COAG E2 $40 \mathrm{~W}$ for DualKnife dissection. The argon plasma coagulation (APC) mode used to mark pseudo-esophageal lesions was FORCED APC $40 \mathrm{~W}$, and the vessel coagulation mode was SOFT COAG E2 $60 \mathrm{~W}$.

The cartridge in the waterjet generator, ERBEJET 2 (Erbe Elektromedizin, Tübingen, Germany), was filled with $0.9 \%$ saline solution with $0.5 \%$ Indigo Carmine. For initial mucosal lifting, a mixture with hyaluronic acid (MucoUp; Seikagaku Co., Tokyo, Japan) was injected with a 23-gauge injection needle (MD47393; Olympus Medical Systems, Tokyo, Japan). Endoclips (HX-610-135L, Olympus Medical Systems, Tokyo, Japan) with string were used for countertraction. The ERBEJET 2 was attached to the VIO $300 \mathrm{D}$.

To find the appropriate water pressure for dissection, we performed preliminary experiments in one pig. Water pressures of 30,50 , and 70 bar were tested for dissection in four virtual esophageal lesions. To further confirm safety, we applied water pressures of 50 and 70 bar directly to the resection bed at an angle of $45^{\circ}$ for 1 minute.

\section{Preparation of the pseudo-lesions and circumferential cutting}

The locations of pseudo-esophageal lesions per pig were as follows: one each left side in the lower, middle, and upper esophagus per technique. This sample number was determined referring to a previous report [25]. The lesions were resected alternately from lower to upper esophagus, i.e. lower and upper esophagus for waterjet ESD (WJ-ESD) and middle esophagus for conventional ESD (C-ESD) in one pig and vice versa in another pig. The distance between each lesion was at least $20 \mathrm{~mm}$. These lesions were marked by APC in an oval shape with an approximately $30-\mathrm{mm}$ longitudinal diameter. The size of each lesion was estimated by the distance marker imprinted on the APC probe. This $30-\mathrm{mm}$ size was decided upon because it was tech- nically easy to treat and it was used in another experimental study [26]. After marking with APC, we injected a mixture of hyaluronic acid with $0.5 \%$ Indigo Carmine around the pseudo-lesion to form an initial elevation. The injections were repeated to secure appropriate mucosal layer lifting and separation from the muscle layer. After a sufficiently high mucosal elevation, a circumferential incision outside the markers was performed as deeply as possible using the DualKnife. Before submucosal dissection, the clip with string was attached to the oral edge of the lesion, and the string was pulled in the oral direction to move the submucosal surface to the front.

\section{Esophageal submucosal dissection using two dissection methods}

A single endoscopist who had extensive experience in therapeutic endoscopy performed all procedures. All procedures were recorded on video. Two techniques, conventional dissection with DualKnife (C-ESD) and waterjet dissection with $\mathrm{Hy}$ bridKnife (WJ-ESD), were performed on three lesions each. In C-ESD, the procedure was initiated from the oral side using Swift Coagulation mode in the usual manner. A mixture of hyaluronic acid was injected as often as needed. In WJ-ESD, the surface of the submucosal layer was dissected by waterjet only, and electrocautery was not used other than at fibrosis-rich sites. During WJ-ESD, the distance to the submucosal surface from the HybridKnife tip was always less than $5 \mathrm{~mm}$ ( $\triangleright$ Video 1 ).

\section{Outcome evaluation in two methods}

The sizes of ESD samples and dissection times were measured. The dissection speeds were calculated as sample area divided by dissection time $[27,28]$. When blood vessels were encountered and bleeding occurred, coagulation was performed with each knife in the SOFT COAG mode (E4, 60 W). When initial coagulation did not work, the bleeding was stopped with additional hemostatic tools, such as coagulation forceps. After the pig had been euthanized, the esophagus was removed and opened with scissors. The esophageal resection beds were checked from the outer side for macroscopic perforations. The ESD specimens and resection beds were stretched and pinned on a cork board immersed in $15 \%$ formalin, and these samples

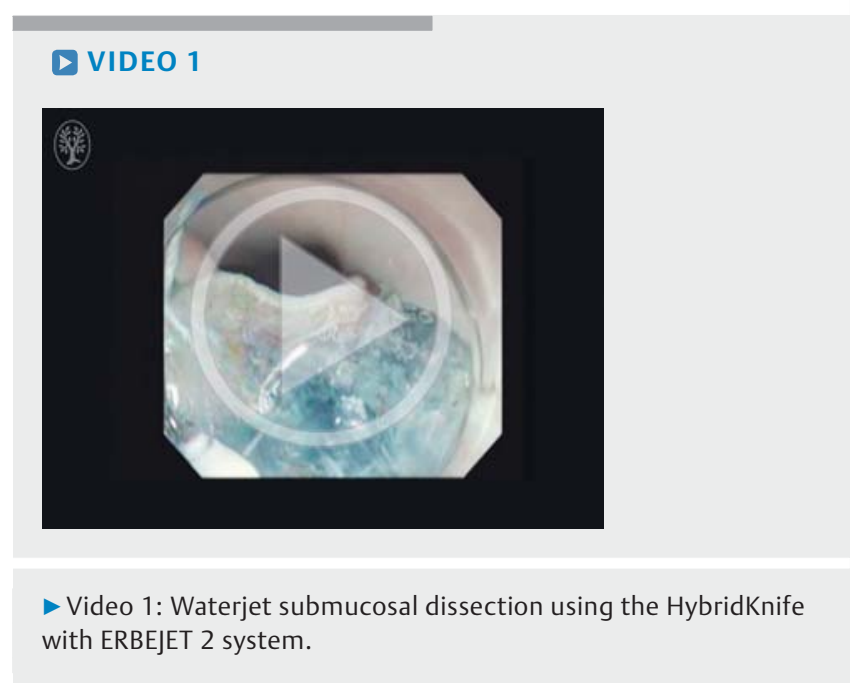




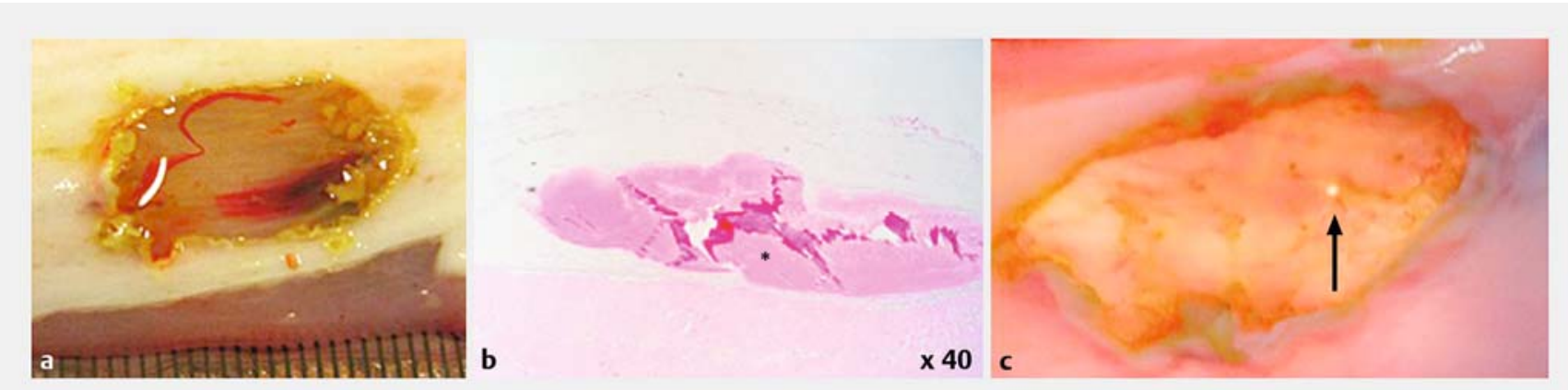

- Fig. 1 Macroscopic and microscopic findings after application of a water pressure of 50 bar (a, b) and 70 bar (c) directly to the muscle layer of a resection bed for 1 minute. No perforation was observed when using 50 bar, but a small perforation occurred when using 70 bar (arrow). This was observed with transmitted light behind the resected bed. * A blood clot.

were cut to 2-mm widths to mount for preparation. Thermal damage to the muscle layer was defined as resection bed muscle fiber degeneration, such as laceration, disruption, or vaporization. The percentages of thermal damage were calculated as the total length of thermal damage divided by the length of the dissected mucosal layer. This was calculated for all 2-mm specimen preparations from each location.

\section{Statistical analysis}

Data were collected and described in actual numbers and percentages. No statistical analysis of significance was performed between the treatment groups because of the small sample sizes.

\section{Results}

\section{Determination of water pressure for dissection}

First we applied 30, 50, and 70 bar water pressures to assess the dissection abilities on one pseudo-lesion. Thirty bar water pressure was too low to dissect submucosa. Then, we performed 70 bar WJ-ESD in two pseudo-lesions and 50 bar WJ-ESD in one pseudo-lesion. Both 70 and 50 bar of water pressure made it possible to dissect submucosa similarly. Intense water backflow, which disturbed the endoscopic front view, occurred more fre- quently when using 70 bar compared with 50 bar. The 50 bar waterjet was appropriate for WJ-ESD because it balanced proper dissection and endoscopic view. No muscle injury was observed when using a water pressure of 50 bar directly to the muscle layer of a resection bed for 1 minute ( $\mathbf{F i g}$. $\mathbf{1 a}, \mathbf{b})$ ), but a perforation occurred at 70 bar ( $\triangleright$ Fig. 1c). Based on these results, 50 bar of water pressure was considered optimal for WJ-ESD of porcine esophagus and was used in subsequent experiments.

\section{Outcomes of the two methods}

The planned ESDs were all successfully performed. The en bloc resection rate was $100 \%$. A total of six ESD samples and six resection beds were obtained (three using C-ESD and three using WJ-ESD). The results are presented in $>$ Table 1 . Resected mucosa sizes were similar in both procedures. Dissection times were longer in the WJ-ESD procedure and dissection speed was slower in the WJ-ESD procedure.

Minor bleeding, which was easily stopped by electrocoagulation using the same knife, was more frequent in the WJ-ESD procedure. Neither uncontrollable bleeding nor perforation occurred, and the use of coagulation forceps was not required in either procedure. No microscopic perforation was observed in either procedure. The thermally damaged areas in the muscle

- Table 1 Outcomes of the two ESD procedures.

\begin{tabular}{|c|c|c|}
\hline & $\begin{array}{l}\text { Conventional ESD } \\
(n=3)\end{array}$ & $\begin{array}{l}\text { Waterjet ESD } \\
(n=3)\end{array}$ \\
\hline Dissected specimen size, $\mathrm{cm}^{2}$ & $10 / 8 / 5$ & $8 / 6 / 7$ \\
\hline Dissection time, min & $9 / 15 / 5$ & $36 / 7 / 32$ \\
\hline Dissection speed, $\mathrm{cm}^{2} / \mathrm{min}$ & $1.1 / 0.5 / 1.0$ & $0.2 / 0.9 / 0.2$ \\
\hline Minor bleeding events treated with electrocoagulation, n & $1 / 1 / 1$ & $6 / 4 / 8$ \\
\hline Device change for hemostasis, $\mathrm{n}$ & $1 / 2 / 0$ & $0 / 0 / 0$ \\
\hline Thermally damaged area in the muscle layer* , \% & $14 / 16 / 7$ & $4 / 6 / 8$ \\
\hline \multicolumn{3}{|c|}{$\begin{array}{l}\text { ESD, endoscopic submucosal dissection. } \\
\text { All values are presented according to the site of ESD: lower/middle/upper esophagus. } \\
{ }^{*} \text { (sum of the lengths of thermal damage in the muscle layer/sum of the lengths of the dissected beds) } \times 100 \text {. Each length was calculated in all specimens for histo- } \\
\text { logical examination, which were sliced in } 2 \text {-mm lengths. }\end{array}$} \\
\hline
\end{tabular}



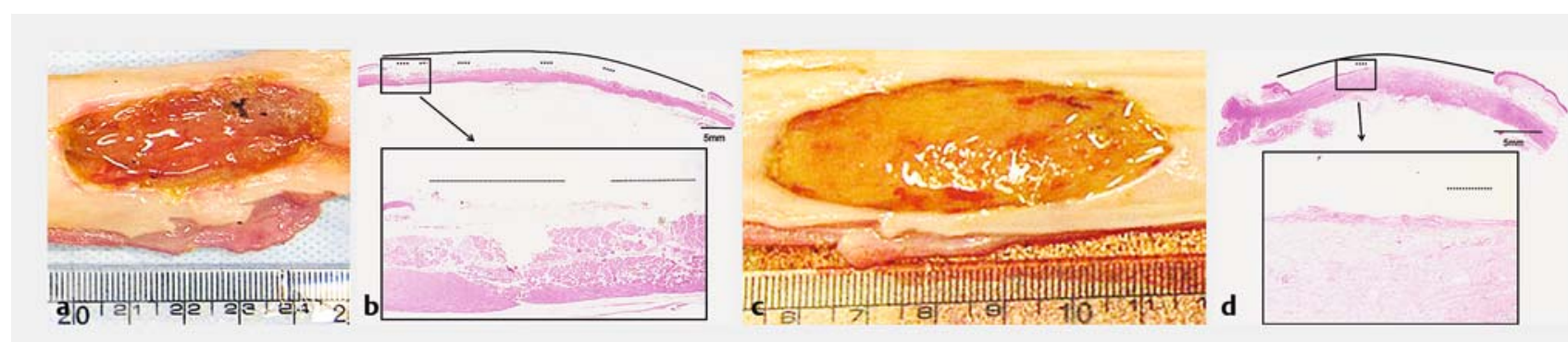

- Fig. 2 Dissected bed specimens from conventional ESD (C-ESD) with DualKnife (a, b) and waterjet ESD (WJ-ESD) with HybridKnife (c, d). a $\mathrm{A}$ bed dissected using conventional ESD appears reddish and edematous, and some coagulation is observed. $\mathbf{b}$ Dotted lines indicate microscopic thermal damage to the muscle layer in the dissected bed (solid line) in C-ESD. c A bed dissected using waterjet appears reddish and edematous, but coagulation is not observed. $\mathbf{d}$ Dotted line indicates microscopic thermal damage to the muscle layer in the dissected bed (solid line) in WJ-ESD. Hematoxylin-eosin staining.

layer were smaller in the lesions of the WJ-ESD procedure as expected ( $\mathbf{F i g}$. 2).

\section{Discussion}

In this experimental study, we safely completed waterjet submucosal dissection using the HybridKnife in porcine esophagus. Waterjet could be used for tissue-sparing blunt submucosal dissection in the esophagus. Bleeding was easily managed using coagulation mode, and no perforation was observed. Much more time was required to complete the procedure with WJ-ESD, but thermal damage to the muscle layer was much milder.

We used 50 bar water pressure in WJ-ESD for porcine esophagus. Higher water pressure enables faster dissection, but it increases the risk of perforation and bleeding. Although a water pressure of 20-30 bar was reported to be feasible for porcine tissue dissection $[25,26]$, we tested higher pressures to speed up dissection as much as was safely feasible. A water pressure of 70 bar caused a macroscopic perforation and additionally intense water backflow, which disturbed the endoscopic front view, and was not considered applicable. Given the harder porcine esophagus, a water pressure of 50 bar is considered appropriate for WJ-ESD. When performing WJ-ESD in patients, the most appropriate waterjet pressure under 50 bar should be determined in a carefully and safely designed clinical trial.

In Japan, esophageal ESD is a widely accepted treatment for early squamous cell carcinoma or high grade intraepithelial neoplasia [2]. However, esophageal ESD is associated with a higher rate of complications, such as perforation or bleeding, than that for other gastrointestinal organs. The esophageal ESD perforation rate is approximately $5.2 \%$ [2], and delayed perforation can occur from thermal damage several days after the procedure. In addition, thermal damage to the muscle layer may cause a scar stenosis even if the resected tissue is small. These esophageal ESD complications could be more serious than those of gastric ESD. To minimize these complications, less electrocautery device usage is reasonable. In this study, we showed that thermal damage to the muscle layer was essentially mild and minor in WJ-ESD. This method may reduce the risk not only of esophageal perforation but also stenosis.
Recently, the efficacy of the Thread-Traction method (T-T method) with clips was reported for esophageal ESD, and this procedure has become widespread in Japan [29-31]. Since the T-T method with clips tenses the submucosal tissue in front of the endoscope, we used this method to transmit the power of the waterjet directly to the edge of dissection and successfully completed the procedure.

WJ-ESD is safe, but it takes more time, even with the T-T method. For future clinical development, WJ-ESD should be combined with conventional methods. For example, after removing soft tissue using the waterjet with the T-T method, hard tissue, e. g. fibrosis, should be treated using electrocoagulation, making the dissection time shorter. Additional injections were not needed for mucosal lifting because the waterjet elevated the submucosal layer concurrently, and this allowed the operator to lighten the work load of needle exchange ( $\downarrow$ Video 1 ). We are now planning prospective clinical studies to assess the combination of electrocoagulation and WJ-ESD.

There are some limitations to this study. First, the sample size was small. Recently, it has become difficult to use many animals from an ethical standpoint. However, we can confirm that three WJ-ESD procedures were safely completed. Second, the porcine esophagus had some fibrosis, and it was somewhat difficult to dissect using only the waterjet. Since the submucosal layer of the human esophagus would be softer than that of a pig, dissection with only the waterjet may be easier in humans. Third, evaluation of healing after WJ-ESD is lacking in the present study because it is impossible to feed pigs for a long time after ESD at our institution. However, the milder pathological changes in dissected specimens suggest better healing after WJ-ESD.

In conclusion, WJ-ESD using the HybridKnife and ERBEJET 2 System is safe with lower thermal damage, and can be combined with conventional submucosal dissection. Clinical trials of WJ-ESD are warranted based on these findings.

\section{Acknowledgments}

The HybridKnife was kindly provided by Erbe Elektromedizin, Ltd. This work was technically supported in part by AMCO and Erbe Elektromedizin, Ltd. The authors wish to thank Professor 
Markus D. Enderle for his excellent advice and all the members of the Division of Gastroenterology and Endoscopy at the University of Tsukuba Hospital for secretarial and technical assistance.

\section{Competing interests}

None

References

[1] Oyama T, Tomori A, Hotta K et al. Endoscopic submucosal dissection of early esophageal cancer. Clin Gastroenterol Hepatol 2005; 3: S6770

[2] Fujishiro M, Yahagi N, Kakushima N et al. Endoscopic submucosal dissection of esophageal squamous cell neoplasms. Clin Gastroenterol Hepatol 2006; 4: 688-694

[3] Ono S, Fujishiro M, Niimi K et al. Long-term outcomes of endoscopic submucosal dissection for superficial esophageal squamous cell neoplasms. Gastrointest Endosc 2009; 70: 860-866

[4] Fujishiro M, Kodashima S, Godo O et al. Endoscopic submucosal dissection for esophageal squamous cell neoplasms. Dig Endosc 2009; 21: $109-115$

[5] Guo HM, Zhang XQ, Chen M et al. Endoscopic submucosal dissection vs endoscopic mucosal resection for superficial esophageal cancer. World J Gastroenterol 2014; 20: 5540 - 5547

[6] Sgourakis G, Gockel I, Lang H. Endoscopic and surgical resection of T1a/T1b esophageal neoplasms: A systematic review. World J Gastroenterol 2013; 19: $1424-1437$

[7] Japan Esophageal Society. Guidelines for diagnosis and treatment of carcinoma of the esophagus. 3rd edn. Tokyo: Kanehara; 2012 (in Japanese)

[8] Gotoda T, Friedland S, Hamanaka $\mathrm{H}$ et al. A learning curve for advanced endoscopic resection. Gastrointest Endosc 2005; 62: 866 867

[9] Choi IJ, Kim CG, Chang H] et al. The learning curve for EMR with circumferential mucosal incision in treating intramucosal gastric neoplasm. Gastrointest Endosc 2005; 62: 860-865

[10] Ono H. Early gastric cancer: diagnosis, pathology, treatment techniques and treatment outcomes. Eur J Gastroenterol Hepatol 2006; 18: $863-866$

[11] Oyama T, Kikuchi Y, Shimaya $S$ et al. Endoscopic mucosal resection using a hooking knife (hooking EMR). Stomach Intest 2002; 44: 1155-1161 (in Japanese)

[12] Isomoto H, Yamaguchi N, Minami H et al. Management of complications associated with endoscopic submucosal dissection/endoscopic mucosal resection for esophageal cancer. Dig Endosc 2013; 25: (Suppl. 01): 29-38

[13] Sato $\mathrm{H}$, Inoue $\mathrm{H}$, Ikeda $\mathrm{H}$ et al. Clinical experience of esophageal perforation occurring with endoscopic submucosal dissection. Dis Esophagus 2014; 27: 617-622

[14] Maeda Y, Hirasawa D, Fujita $N$ et al. Mediastinal emphysema after esophageal endoscopic submucosal dissection: its prevalence and clinical significance. Dig Endosc 2011; 23: 221-226
[15] Maeda Y, Hirasawa D, Fujita T et al. A pilot study to assess mediastinal emphysema after esophageal endoscopic submucosal dissection with carbon dioxide insufflations. Endoscopy 2012; 44: 565-571

[16] Neuhaus H, Wirths K, Schenk M et al. Randomized controlled study of EMR versus endoscopic submucosal dissection with a water-jet HybridKnife of esophageal lesions in a porcine model. Gastrointest Endosc 2009; 70: $112-120$

[17] Lingenfelder T, Fischer K, Sold MG et al. Combination of water-jet dissection and needle-knife as a hybrid knife simplifies endoscopic submucosal dissection. Surg Endosc 2009; 23: 1531 - 1535

[18] Yahagi N, Neuhaus H, Schumacher B et al. Comparison of standard endoscopic submucosal dissection (ESD) versus an optimized ESD technique for the colon: an animal study. Endoscopy 2009; 41: $340-$ 345

[19] Femandez-Esparrach G, Matthes EL, Maurice D et al. A novel device for endoscopic submucosal dissection that combines water-jet submucosal hydrodissection and elevation with electrocautery: initial experience in a porcine model. Gastrointest Endosc 2010; 3: 615-618

[20] Fukami N, Ryu CB, Said S et al. Prospective, randomized study of conventional versus HybridKnife endoscopic submucosal dissection methods for the esophagus: an animal study. Gastrointest Endosc 2011; 6: $1246-1253$

[21] Schumacher B, Charton JP, Nordmann T et al. Endoscopic submucosal dissection of early gastric neoplasia with a water jet-assisted knife: a Western, single-center experience. Gastrointest Endosc 2012; 6: $1166-1174$

[22] Repici A, Hassan C, Pagano N et al. High efficacy of endoscopic submucosal dissection for rectal laterally spreading tumors larger than 3 cm. Gastrointest Endosc 2013; 1: 96 - 101

[23] Zhou PH, Schumacher B, Yao LQ et al. Conventional vs. waterjet-assisted endoscopic submucosal dissection in early gastric cancer: a randomized controlled trial. Endoscopy 2014; 10: 836-843

[24] De-la-Peña J, Calderón Á, Esteban JM et al. Experimental study of hybrid-knife endoscopic submucosal dissection (ESD) versus standard ESD in a Western country. Rev Esp Enferm Dig 2014; 106: 98 - 102

[25] Sato C, Nakano T, Nakagawa A et al. Experimental application of pulsed laser-induced water jet for endoscopic submucosal dissection: Mechanical investigation and preliminary experiment in swine. Dig Endosc 2013; 25: 255-263

[26] Lepilliez V, Robles-Medranda C, Ciocirlan M et al. Water-jet dissector for endoscopic submucosal dissection in an animal study: outcomes of the continuous and pulsed modes. Surg Endosc 2013; 27: 2921 2927

[27] González N, Parra-Blanco A, Villa-Gómez M et al. Gastric endoscopic submucosal dissection: from animal model to patient. World J Gastroenterol 2013; 19: 8326-8334

[28] Pioche M, Ciocirlan M, Lépilliez V et al. High-pressure jet injection of viscous solutions for endoscopic submucosal dissection: a study on ex vivo pig stomachs. Surg Endosc 2014; 28: 1742 - 1747

[29] Oyama T. Counter traction makes endoscopic submucosal dissection easier. Clin Endosc 2012; 45: 375-378

[30] Ota M, Nakamura T, Hayashi K et al. Usefulness of clip traction in the early phase of esophageal endoscopic submucosal dissection. Dig Endosc 2012; 24: $315-318$

[31] Koike $Y$, Hirasawa D, Fujita $N$ et al. Usefulness of the thread-traction method in esophageal endoscopic submucosal dissection: Randomized controlled trial. Dig Endosc 2015; 27: 303-309 